\title{
제과제빵기계의 열전달 해석
}

\author{
이종선 ${ }^{*}$ \\ ${ }^{1}$ 대진대학교 컴퓨터응용기계설계공학과
}

\section{Heat Transfer Analysis of Bakery Machine}

\author{
Jong-sun Lee L $^{*}$ \\ ${ }^{1}$ Computer Aided Mechanical Design Engineering, DaeJin University
}

요 약 본 논문의 목적은 제과제빵기계인 다기능 도우 컨디셔너의 열전달 해석에 있다. 도우 컨디셔너는 제과제빵 의 원료인 생지(dough)를 숙성시키는 중요한 기계로서 사용량이 증가하고 있다.

새로운 형태의 다기능 도우 컨디셔너를 제작하기 위하여 자동 설계프로그램인 Solidworks를 활용하여 설계하였으며 이를 근거로 3차원 유한요소 해석코드인 ANSYS를 활용하여 열전달 해석을 수행하였다. 해석결과로서 다기능 도우 컨디셔너의 내부온도와 열유속을 구하였으며 이 결과는 다기능 도우 컨디셔너의 제작에 활용되었다.

\begin{abstract}
This research aims to do heat transfer analysis on multi-functional dough conditioner. The dough conditioner is a key bakery machine for the maturation of dough which is raw material of bakery and also it's amount of used has been increased. Solidworks which is one of automatic design programs is applied to design in order to manufacture the multi-functional dough conditioner, and ANSYS which is a three dimensional finite element analysis code is used for the heat transfer analysis. Inside temperatures and heat fluxes are obtained as the results of heat transfer analysis and the results are contributed significantly in manufacturing the multi-functional dough conditioner.
\end{abstract}

Key Words : Bakery Machine, Heat Transfer Analysis, Heat Flux, Inside Temperature, Self Test

\section{1. 서론}

제과제빵기계 산업은 유럽의 제과제빵 기술이 국내에 도입된 이래 각종 제과제빵 기계가 개발되었으나 엄격한 의미에서 선진국에 비해 제과제빵기계 산업이 낙후되어 있다. 따라서 많은 제과제빵기계가 수입되고 있으며 한국 의 제과제빵기계를 선진국으로 수출하기에는 역부족이다.

개발대상인 다기능 도우 컨디셔너는 신기술 제품으로 선진국에서 개발되지 못한 제품이다. 기존제품은 해동과 발효기능으로 한정된 기능과 프로그램을 갖고 있으나 개 발품은 급속냉동고, 숙성고, 발효기, 도우 컨디셔너의 성
능을 갖고 자가진단기능을 갖춘 장비로 설치 시 좁은 공 간의 활용도가 높고 장비의 구입가격 절감, 인력 감축 등 혁신적인 제품으로 평가할 수 있다.

경제 산업적 측면에서는 점차 서구화되고 있는 식문화 에서 필연적으로 많은 베이커리 장비가 필요하며 3 4 종 류의 장비의 역할을 담당하는 다기능 장비로 대체함으로 써 원가절감에 기여할 수 있고 좁은 공간에 설치가 가능 하므로 주방의 소요면적을 줄일 수 있다.

본 논문의 목적은 다기능 도우 컨디셔너의 열전달 해 석에 있다. 도우 컨디셔너는 제과제빵의 원료인 생지 (dough)를 숙성시키는 중요한 기계로서 사용량이 증가하 고 있다.

이 논문은 2012학년도 대진대학교 학술연구비 지원에 의한 것임.

*Corresponding Author: Jong-sun Lee

Tel: +82-11-794-1978 email: jongsun@daejin.ac.kr

접수일 12년 09월 14일 수정일 12년 10월 04일 
새로운 기능의 다기능 도우 컨디셔너를 제작하기 위하 여 자동 설계프로그램인 Solidworks[1]를 활용하여 설계 하였으며 이를 근거로 3 차원 유한요소 해석코드인 ANSYS[2-3]를 활용하여 열전달 해석[4-6]을 수행하였다. 해석결과로서 다기능 도우 컨디셔너의 내부온도와 열유 속(heat flux)을 구하였으며 이 결과는 다기능 도우 컨디 셔너의 제작에 활용되었다.

\section{2. 제과제빵기계의 모델링}

제과제빵기계인 다기능 도우 컨디셔너는 SolidWorks 를 사용하여 모델링하였다. 모델링은 원활한 해석을 위하 여 간략화 시키고 불필요한 부분은 제거하였으며 하나의 모델에 상부와 하부 2 개의 칸이 있고 같은 기계를 적재하 여 총 6 8개 까지 사용할 수 있으나 모두 같은 작동을 하므로 상부와 하부 둘 중에 한 부분만 모델링하였다. Fig. 1은 다기능 도우 컨디셔너의 형상을 나타내며 Fig. 2 는 다기능 도우 컨디셔너의 내부를 나타낸다.

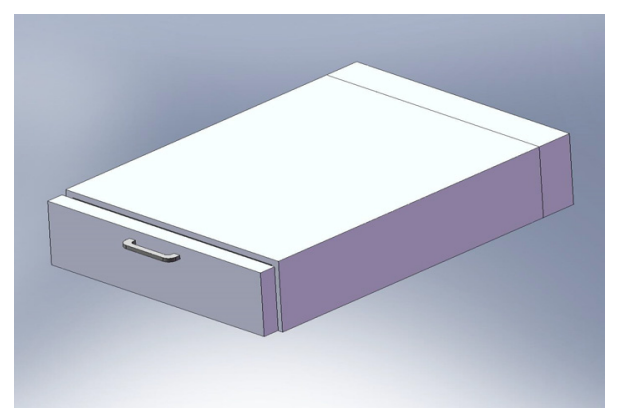

[그림 1] 다기능 도우 컨디셔너의 형상

[Fig. 1] Geometry of multi-functional dough conditioner

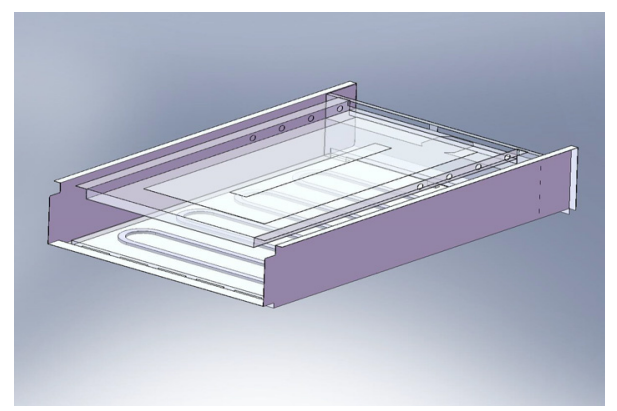

[그림 2] 다기능 도우 컨디셔너의 내부

[Fig. 2] Inside view of multi-functional dough conditioner

\section{3. 열전달 해석}

다기능 도우 컨디셔너의 열전달 해석은 3 차원 유한요 소해석 코드인 ANSYS를 활용하였으며 다기능 도우 컨 디셔너 내부에서 시간에 따라 변하는 온도분포와 열유속 을 구하였다. 해석조건은 가열상태와 냉각상태 2 가지 방 식으로 구분하였다. 상부 열판에 $90^{\circ} \mathrm{C}$ 의 열이 발생하는 경우와 하부 냉각 코일이 $-10^{\circ} \mathrm{C}$ 로 냉각 할 경우로 나누 어 해석하였고 시간은 총 60 분을 5 분 간격으로 나누어 온도분포와 열유속의 변화과정을 결과로 얻었다. 본 해석 에 사용된 재질은 Stainless Steel 로서 물성치[7]는 Table 1 과 같다.

[표 1] 물성치

[Table 1] Material properties of Stainless Steel

\begin{tabular}{|c|c|}
\hline \multicolumn{2}{|c|}{ Structural } \\
\hline Young's Modulus & $2 . \mathrm{e}+011 \mathrm{~Pa}$ \\
\hline Poisson's Ratio & 0.3 \\
\hline Density & $7850 . \mathrm{kg} / \mathrm{m}^{3}$ \\
\hline Thermal Expansion & $1.2 \mathrm{e}-005 /{ }^{\circ} \mathrm{C}$ \\
\hline Tensile Yield Strength & $2.5 \mathrm{e}+008 \mathrm{~Pa}$ \\
\hline Compressive Yield Strength & $2.5 \mathrm{e}+008 \mathrm{~Pa}$ \\
\hline Tensile Ultimate Strength & $4.6 \mathrm{e}+008 \mathrm{~Pa}$ \\
\hline Compressive Ultimate Strength & $0 . \mathrm{Pa}$ \\
\hline \multicolumn{2}{|c|}{ Thermal } \\
\hline Thermal Conductivity & $60.5 \mathrm{~W} / \mathrm{m} \cdot{ }^{\circ} \mathrm{C}$ \\
\hline Specific Heat & $434 . \mathrm{J} / \mathrm{kg} \cdot{ }^{\circ} \mathrm{C}$ \\
\hline Electromagnetics \\
\hline Relative Permeability & 10000 \\
\hline Resistivity & $1.7 \mathrm{e}-007 \mathrm{Ohm} \cdot \mathrm{m}$ \\
\hline
\end{tabular}

\section{1 가열상태의 해석}

Fig. 3은 다기능 도우 컨디셔너 모델의 메쉬 형성을 나 타내며 114,076 개의 절점과 57,426 개의 요소로 구성되어 있다.

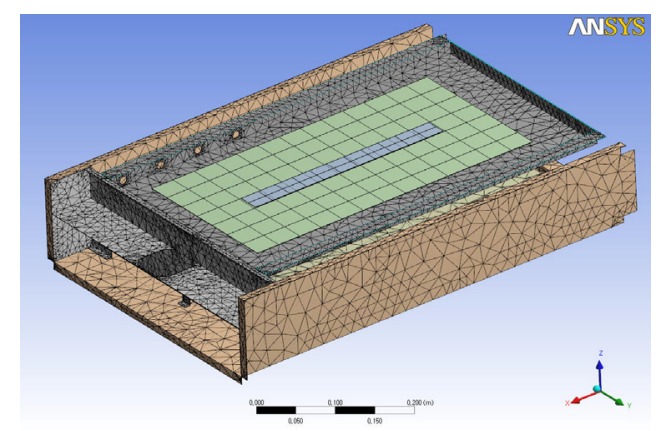

[그림 3] Mesh 형성

[Fig. 3] Mesh generation 
Table 2는 해석조건으로서 주변 공기의 대류조건으로 $22^{\circ} \mathrm{C}$ 의 온도를 설정하였고, 열판에 $90^{\circ} \mathrm{C}$ 의 온도를 가하 고 60 분 동안 5 분 간격으로 열전달 해석을 수행하였다.

[표 2] 해석조건

[Table 2] Analysis condition

\begin{tabular}{|c|c|c|}
\hline Object Name & Temperature & Convection \\
\hline State & \multicolumn{2}{|r|}{ Fully Defined } \\
\hline \multicolumn{3}{|c|}{ Scope } \\
\hline Scoping Method & \multicolumn{2}{|c|}{ Geometry Selection } \\
\hline Geometry & 6 Faces & 268 Faces \\
\hline \multicolumn{3}{|c|}{ Definition } \\
\hline Type & Temperature & Convection \\
\hline Magnitude & $\begin{array}{l}\text { 90. }{ }^{\circ} \mathrm{C} \text { (step } \\
\text { applied) }\end{array}$ & \\
\hline Film Coefficient & & $\begin{array}{c}\text { Stagnant Air - Simplified } \\
\text { Case }\end{array}$ \\
\hline Ambient Temperature & & 22. ${ }^{\circ} \mathrm{C}$ (step applied) \\
\hline
\end{tabular}

Fig. 4 10은 다기능 도우 컨디셔너의 경계조건 그리 고 시간별 온도분포와 열유속의 결과이다.

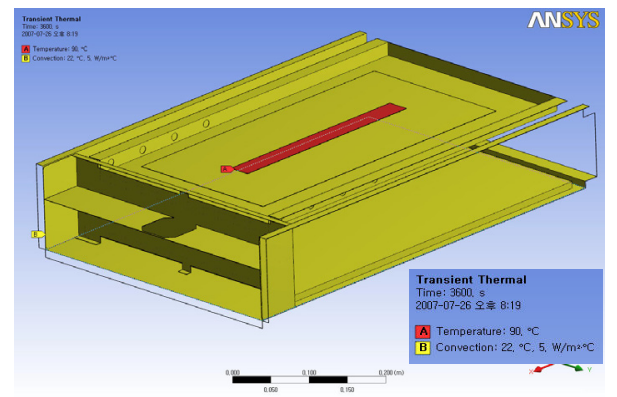

[그림 4] 다기능 도우 컨디셔너의 경계조건

[Fig. 4] Boundary condition of multi-functional dough conditioner

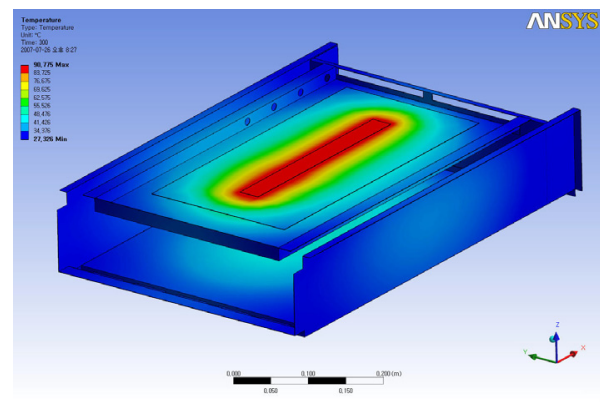

[그림 5] 온도분포(5분 경과)

[Fig. 5] Temperature distribution at 5 minutes

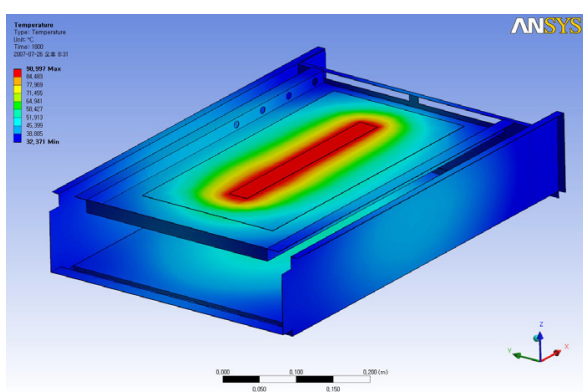

[그림 6] 온도분포(30분 경과)

[Fig. 6] Temperature distribution at 30 minutes

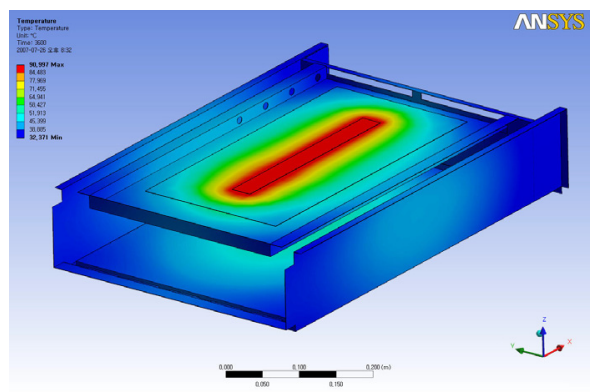

[그림 7] 온도분포(60분 경과)

[Fig. 7] Temperature distribution at 60 minutes

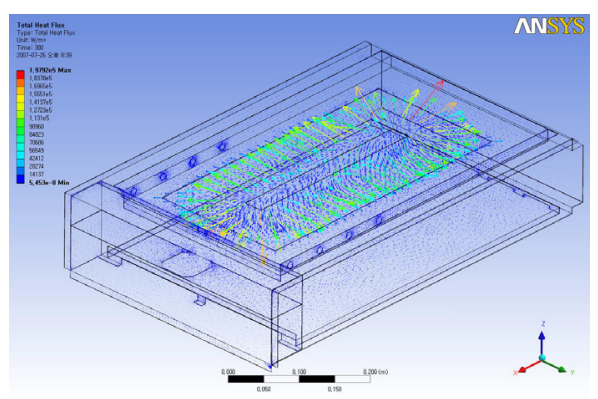

[그림 8] 열유속(5분 경과)

[Fig. 8] Heat flux at 5 minutes

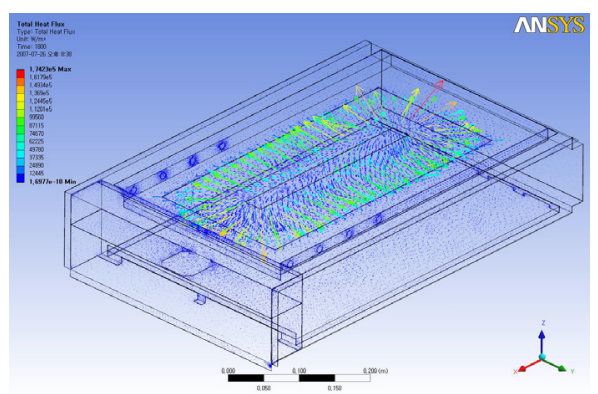

[그림 9] 열유속(30분 경과)

[Fig. 9] Heat flux at 30 minutes 


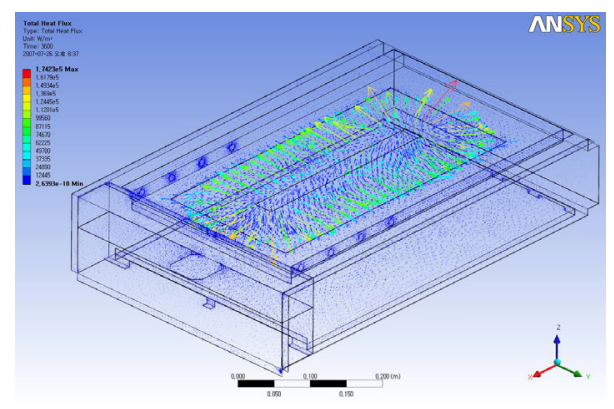

[그림 10] 열유속(60분 경과)

[Fig. 10] Heat flux at 60 minutes

Table 3, 4는 각각 시간변화에 따른 온도분포와 열유 속을 나타낸다.

[표 3] 온도분포의 결과

[Table 3] Temperature distribution results

\begin{tabular}{|c|c|c|c|}
\hline Step & Sec & Minimum $\left[{ }^{\circ} \mathrm{C}\right]$ & Maximum $\left[{ }^{\circ} \mathrm{C}\right]$ \\
\hline 1 & 300 & 27.326 & 90.775 \\
\hline 2 & 600 & 30.541 & 91.04 \\
\hline 3 & 900 & 31.791 & 91.009 \\
\hline 4 & 1200 & 32.199 & 91 \\
\hline 5 & 1500 & 32.326 & 90.997 \\
\hline 6 & 1800 & 32.371 & 90.997 \\
\hline 7 & 2100 & 32.371 & 90.997 \\
\hline 8 & 2400 & 32.371 & 90.997 \\
\hline 9 & 2700 & 32.371 & 90.997 \\
\hline 10 & 3000 & 32.371 & 90.997 \\
\hline 11 & 3300 & 32.371 & 90.997 \\
\hline 12 & 3600 & 32.371 & 90.997 \\
\hline
\end{tabular}

[표 4] 열유속의 결과

[Table 4] Heat flux results

\begin{tabular}{|c|c|c|c|}
\hline Step & Sec & Minimum $\left[\mathrm{W} / \mathrm{m}^{2}\right]$ & Maximum $\left[\mathrm{W} / \mathrm{m}^{2}\right]$ \\
\hline 1 & 300 & $5.45 \mathrm{E}-08$ & $1.98 \mathrm{E}+05$ \\
\hline 2 & 600 & $2.85 \mathrm{E}-08$ & $1.79 \mathrm{E}+05$ \\
\hline 3 & 900 & $9.44 \mathrm{E}-10$ & $1.75 \mathrm{E}+05$ \\
\hline 4 & 1200 & $4.27 \mathrm{E}-10$ & $1.75 \mathrm{E}+05$ \\
\hline 5 & 1500 & $2.62 \mathrm{E}-10$ & $1.74 \mathrm{E}+05$ \\
\hline 6 & 1800 & $1.70 \mathrm{E}-10$ & $1.74 \mathrm{E}+05$ \\
\hline 7 & 2100 & $1.68 \mathrm{E}-10$ & $1.74 \mathrm{E}+05$ \\
\hline 8 & 2400 & $4.38 \mathrm{E}-10$ & $1.74 \mathrm{E}+05$ \\
\hline 9 & 2700 & $4.68 \mathrm{E}-10$ & $1.74 \mathrm{E}+05$ \\
\hline 10 & 3000 & $4.43 \mathrm{E}-10$ & $1.74 \mathrm{E}+05$ \\
\hline 11 & 3300 & $5.32 \mathrm{E}-10$ & $1.74 \mathrm{E}+05$ \\
\hline 12 & 3600 & $2.64 \mathrm{E}-10$ & $1.74 \mathrm{E}+05$ \\
\hline
\end{tabular}

결과 값을 보면 온도분포는 열원인 열판을 중심으로 주변으로 퍼져나가는 것을 알 수 있고 시간이 지남에 따 라 최소온도 지점의 온도가 조금씩 상승하는 것을 확인 할 수 있다. 시간의 변화에 따라서 온도가 점차 상승하지 만 $1800 \mathrm{sec}$ 후에는 온도가 일정하게 유지되는 정상상태 에 도달하였다. 열유속의 경우 최소값은 시간에 따른 결 과가 불규칙하지만 최대값은 $900 \mathrm{sec}$ 에서 정상상태에 도 달하였다.

\section{2 냉각상태의 해석}

다기능 도우 컨디셔너 모델은 121,220 개의 절점과 60,148 개의 요소로 구성되어 있다. Table 5 는 해석조건으 로서 주변 공기의 대류조건으로 $22^{\circ} \mathrm{C}$ 의 온도를 설정하 였고, 냉각코일에 $-10^{\circ} \mathrm{C}$ 의 온도를 가하고 60 분 동안 5 분 간격으로 열전달 해석을 수행하였다.

[표 5] 해석조건

[Table 5] Analysis condition

\begin{tabular}{|c|c|c|}
\hline Object Name & Temperature & Convection \\
\hline State & \multicolumn{2}{|c|}{ Fully Defined } \\
\hline \multicolumn{3}{|c|}{ Scope } \\
\hline Scoping Method & Geometry Selection \\
\hline Geometry & 34 Faces & 341 Faces \\
\hline \multicolumn{3}{|c|}{ Definition } \\
\hline Type & Temperature & Convection \\
\hline Magnitude & $\begin{array}{c}-10 .{ }^{\circ} \mathrm{C} \text { (step } \\
\text { applied) }\end{array}$ \\
\hline Film Coefficient & & $\begin{array}{c}\text { Stagnant Air - } \\
\text { Simplified Case }\end{array}$ \\
\hline $\begin{array}{c}\text { Ambient } \\
\text { Temperature }\end{array}$ & $22 .{ }^{\circ} \mathrm{C}$ (step applied) \\
\hline
\end{tabular}

Fig. $11 \sim 17$ 은 다기능 도우 컨디셔너의 경계조건 그리 고 시간별 온도분포와 열유속의 결과이다.

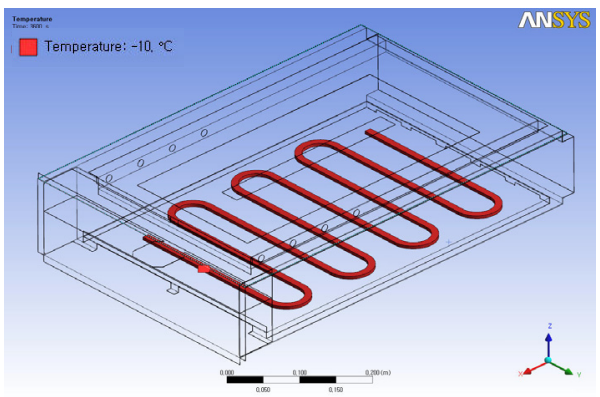

[그림 11] 다기능 도우 컨디셔너의 경계조건

[Fig. 11] Boundary condition of multi-functional dough conditioner 


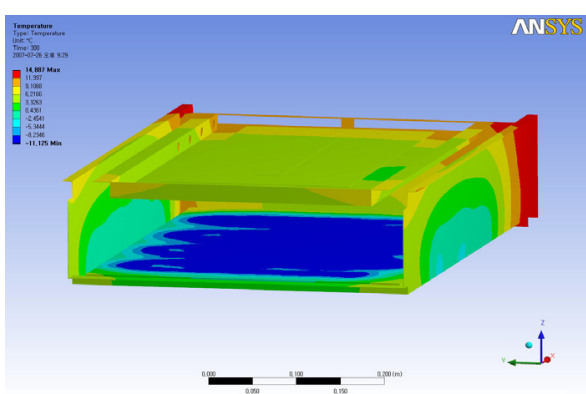

[그림 12] 온도분포(5분 경과)

[Fig. 12] Temperature distribution at 5 minutes

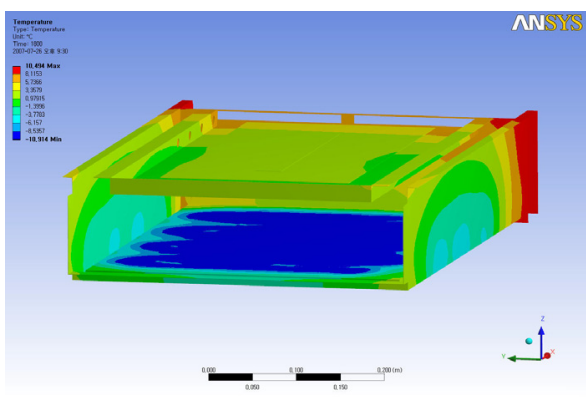

[그림 13] 온도분포(30분 경과)

[Fig. 13] Temperature distribution at 30 minutes

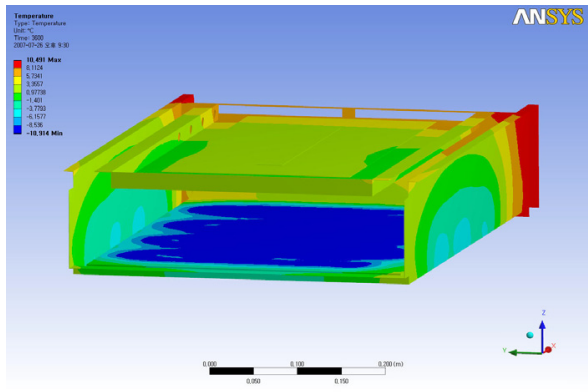

[그림 14] 온도분포(60분 경과)

[Fig. 14] Temperature distribution at 60 minutes

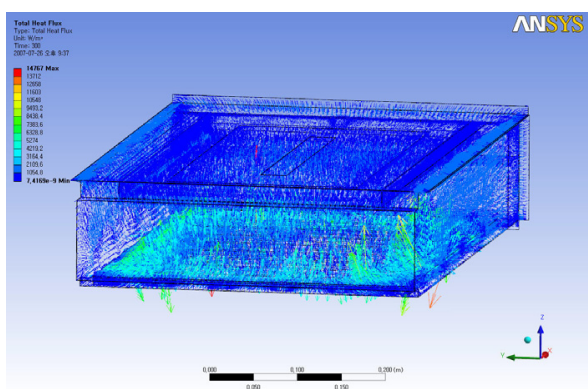

[그림 15] 열유속(5분 경과)

[Fig. 15] Heat flux at 5 minutes

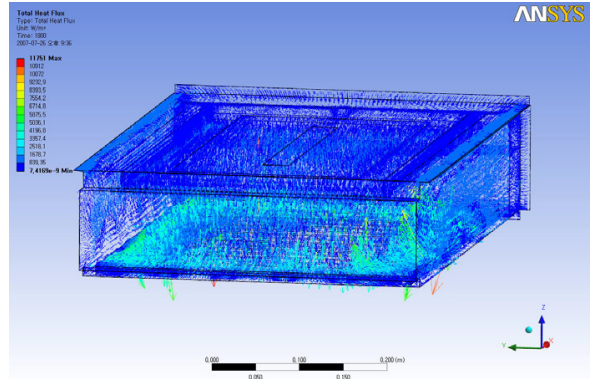

[그림 16] 열유속(30분 경과)

[Fig. 16] Heat flux at 30 minutes

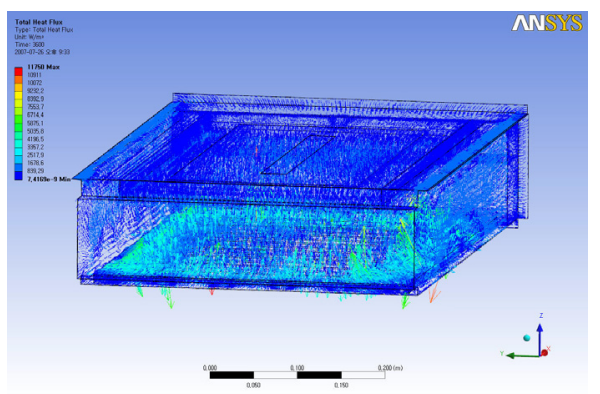

[그림 17] 열유속(60분 경과)

[Fig. 17] Heat flux at 60 minutes

Table 6, 7은 각각 시간변화에 따른 온도분포와 열유 속을 나타낸다.

[표 6] 온도분포의 결과

[Table 6] Temperature distribution results

\begin{tabular}{|c|c|c|c|}
\hline Step & Sec & Minimum $\left[{ }^{\circ} \mathrm{C}\right]$ & Maximum $\left[{ }^{\circ} \mathrm{C}\right]$ \\
\hline 1 & 300 & -11.125 & 14.887 \\
\hline 2 & 600 & -10.955 & 11.711 \\
\hline 3 & 900 & -10.923 & 10.786 \\
\hline 4 & 1200 & -10.916 & 10.557 \\
\hline 5 & 1500 & -10.915 & 10.505 \\
\hline 6 & 1800 & -10.914 & 10.494 \\
\hline 7 & 2100 & -10.914 & 10.491 \\
\hline 8 & 2400 & -10.914 & 10.491 \\
\hline 9 & 2700 & -10.914 & 10.491 \\
\hline 10 & 3000 & -10.914 & 10.491 \\
\hline 11 & 3300 & -10.914 & 10.491 \\
\hline 12 & 3600 & -10.914 & 10.491 \\
\hline
\end{tabular}


[표 7] 열유속의 결과

[Table 7] Heat flux results

\begin{tabular}{|c|c|c|c|}
\hline Step & Sec & Minimum $\left[\mathrm{W} / \mathrm{m}^{2}\right]$ & Maximum $\left[\mathrm{W} / \mathrm{m}^{2}\right]$ \\
\hline 1 & 300 & $7.42 \mathrm{E}-09$ & 14767 \\
\hline 2 & 600 & $7.42 \mathrm{E}-09$ & 12269 \\
\hline 3 & 900 & $7.42 \mathrm{E}-09$ & 11853 \\
\hline 4 & 1200 & $7.42 \mathrm{E}-09$ & 11771 \\
\hline 5 & 1500 & $7.42 \mathrm{E}-09$ & 11754 \\
\hline 6 & 1800 & $7.42 \mathrm{E}-09$ & 11751 \\
\hline 7 & 2100 & $7.42 \mathrm{E}-09$ & 11750 \\
\hline 8 & 2400 & $7.42 \mathrm{E}-09$ & 11750 \\
\hline 9 & 2700 & $7.42 \mathrm{E}-09$ & 11750 \\
\hline 10 & 3000 & $7.42 \mathrm{E}-09$ & 11750 \\
\hline 11 & 3300 & $7.42 \mathrm{E}-09$ & 11750 \\
\hline 12 & 3600 & $7.42 \mathrm{E}-09$ & 11750 \\
\hline
\end{tabular}

결과 값을 보면 온도분포는 냉각코일을 중심으로 주변 으로 퍼져나가는 것을 알 수 있고 시간이 지남에 따라 최 대온도 지점의 온도가 조금씩 떨어졌다. 시간의 변화에 따라서 온도가 일정 온도 이하로 떨어지지만 $1800 \mathrm{sec}$ 후 에는 일정하게 유지되는 정상상태에 도달하였다. 열유속 의 경우 최소값은 일정하지만 최대값은 $2100 \mathrm{sec}$ 에서 정 상상태에 도달하였다.

\section{4. 결론}

다기능 도우 컨디셔너의 열전달 해석을 위하여 SolidWorks를 활용하여 모델링 하였고, 3차원 유한요소 해석코드인 ANSYS를 활용하여 수행하였으며 그 결과는 다음과 같다.

(1) 상부 열판에 $90^{\circ} \mathrm{C}$ 의 열이 작용하는 가열상태 해 석의 경우 온도분포가 열판을 중심으로 퍼져 나가 는 결과를 알 수 있었다. 열유속도 열판 주변에서 높게 나타났다.

(2) 하부 냉각코일이 $-10^{\circ} \mathrm{C}$ 로 냉각되는 냉각상태 해석 의 경우 냉각 코일을 중심으로 코일 주위에는 낮은 온도가 분포하였고 멀어 질수록 온도가 높게 분포 하였다. 열유속도 냉각 코일 주위에서 높게 분포했 다.

(3) $90^{\circ} \mathrm{C}$ 와 $-10^{\circ} \mathrm{C}$ 의 온도가 작용하는 두 가지 경우 모두에서 온도분포와 열유속이 일정 시간이 지난 후에는 정상상태에 도달하였다.

\section{References}

[1] Solidworks User's Manual Revision 3.0, Solidworks Co., 2006.

[2] ANSYS User's Manual Ver.12.1, ANSYS Inc., 2010.

[3] Park chulwoo, Hong chulhyun, "User Guide of ANSYS Workbench“, Intervision, 2008.

[4] Lee jongsun, Baik doosung, "CFD Analysis of Unibaker Oven", Journal of the Korea Academia-Industrial cooperation Society, Vol.5, No.5, pp.371-376, 2004.

[5] Lee jongsun, "A Study on the Optimum Shape of Rope Brake”, TRANSACTIONS of KSMTE, Vol.14, No.1, pp.101-107, 2005.

[6] Lee jongsun, "Computational Fluid Dynamics of Hydraulic Valve Meter", Journal of the Korea Academia-Industrial cooperation Society, Vol.13, No.5, pp.1963-1968, 2012.

[7] James shakelford and William Alexander, "Material Science and Engineering Hand Book", CRC Press, 1994.

이 종 선(Jong-Sun Lee)

[종신회원]

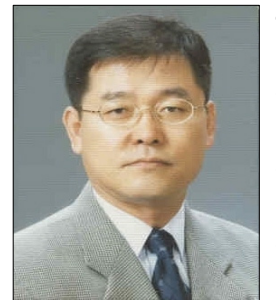

- 1982년 2월 : 국민대학교 기계설 계학과 (공학사)

- 1984년 2월 : 국민대학교 기계공 학과 (공학석사)

- 1996년 2월 : 국민대학교 기계설 계학과(공학박사)

- 1996년 3월 현재 : 대진대학 교 컴퓨터응용기계설계공학과 교수

<관심분야>

최적설계, 생산공학 